\title{
Neuroimaging Outcomes of Brain Training Trials
}

\author{
Chao Suo and Michael J. Valenzuela \\ Regenerative Neuroscience Group, School of Psychiatry \& Brain and \\ Ageing Research Program, University of New South Wales \\ Australia
}

\section{Introduction}

The brain remains plastic throughout the human lifespan. This unique property holds great promise for the better treatment of cognitive disorders, and forms the basis for behavioural interventions aimed at promoting mental function that may help delay and prevent the onset of dementia. Brain training (BT) is a direct method for targeting brain plasticity that employs repetitive cognitive exercises. Over the past decade increasing evidence has accumulated that BT can lead to clinical and cognitive benefits in psychiatric samples (McGurk et al., 2005, 2007), as well as in healthy older individuals (Valenzuela \& Sachdev, 2009). However, the neurobiological mechanisms underlying these clinical benefits are not well understood. Advances in neuroimaging therefore has potential for revealing the complex in vivo structural, functional and metabolic brain changes that accompany BT. The aim of this systematic review was to compare and integrate results of several recent clinical trials of BT that have employed Magnetic Resonance Imaging (MRI), with a particular emphasis on design and technical issues. These studies are beginning to provide fascinating insights into the nature of BT effects on the human brain.

\section{Definition of brain training}

The wider cognitive intervention field abounds with multiple ill-defined terms that have hampered their development and validation, and can also explain mixed findings to date (Gates \& Valenzuela, 2010). Clare and Woods divide this general area into 'cognitive rehabilitation', 'cognitive stimulation', or 'cognitive training' (CT) (Clare \& Woods, 2004). We have proposed a specific operational definition for cognitive training (CT) to include cognitive interventions that meet the following four criteria: 1 ) involves repeated practice, 2 ) on tasks with an inherent problem, 3) using standardized exercises, and 4) that specifically target a cognitive domain (Gates \& Valenzuela, 2010). Here, the terms BT and CT are identical and are used interchangeably.

\section{Method}

\subsection{Search strategy}

The Medline (1996 - 04/2011) database was searched for original research articles in English that met the following criteria. (a) 'brain training', 'cognitive training', 'cognitive 
intervention', 'cognitive exercise', 'mental exercise', 'cognitive activity' or 'cognitive stimulation', and (b) 'individuals', 'adults', 'persons', 'subjects', but no 'children' or 'teenagers', and (c) 'Magnetic Resonance Image', 'MRI' or 'brain scans'. Combined intervention, subject, and method terms were searched across all fields and produced 144 studies. The title and abstract of these studies were reviewed to identify potentially relevant trials, and these were supplemented by manual checking through reference lists of published reports.

\subsection{Inclusion criteria \& study quality}

Studies were selected for review if they met the following criteria: i) comprised a longitudinal clinical trial with either a randomized controlled trial (RCT) design or uncontrolled clinical trial design (UCT), ii) sample included only healthy individuals not selected against clinical psychiatric criteria, iii) had MRI assessment at least at baseline (before training) and at post-training, and iv) the nature of the intervention met our definition for cognitive training (described above). The qualities of included studies were assessed against CONSORT 2001 criteria for clinical trials (www.consort-statement.org).

\section{Results}

\subsection{Search results}

After reviewing the 144 abstracts returned by our search, nine studies containing ten trials met our criteria. These included 7 RCT and 3 UCT. Details are provided in Table 1.

\subsection{Study quality}

Quality of studies varied between 13.5 and 19.5 (out of a maximum of 24). The main limiting factors were unspecified sample size calculations, or details about method of randomizing and blinding. CONSORT criteria scores for RCTs are provided in Table $\mathbf{1}$ (maximum $=25$ ).

\subsection{Subjects}

There were a total of 309 subjects included in the ten identified trials, split between training $(\mathrm{N}=168)$ and control groups $(\mathrm{N}=138)$. Sample size varied from 10 (Dahlin et al., 2008; Takeuchi et al., 2010) to 58 (Mozolic et al., 2010). Studies divided into three main groups based on age of participants: five studies of young adults with average age of 20-30 years (Dahlin et al., 2008; Erickson et al., 2007a; Olesen et al., 2004; Takeuchi et al., 2010), three studies of elderly subjects with mean age over 60 years (Engvig et al., 2010; Mozolic et al., 2010; Valenzuela et al., 2003), and two studies that combined both elderly and young adult age groups (Erickson et al., 2007b; Lovden et al., 2010). Recruitment source was also variable: young adult subjects were mainly university students, while elderly subjects were from the community based on newspaper advertisements (Dahlin et al., 2008; Engvig et al., 2010; Lovden et al., 2010). All subjects were cognitively-intact.

\subsection{Nature of brain training}

Because two studies used the same BT protocols (Erickson et al., 2007a, 2007b), a total of nine protocols were reviewed. These could be distinguished on the basis of implementation, either computer-based exercises (Dahlin et al., 2008; Erickson et al., 2007a, 2007b; Lovden et al., 2010; Olesen et al., 2004; Takeuchi et al., 2010), or non-computerized 'paper-and-pencil' exercises (Engvig et al., 2010; Valenzuela et al., 2003). Computerized BT most commonly 


\begin{tabular}{|c|c|c|c|c|c|c|c|c|c|}
\hline 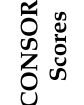 & 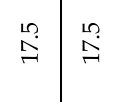 & $\stackrel{\infty}{\sim}$ & $\frac{\varangle}{z}$ & $\frac{\varangle}{\mathrm{z}}$ & $\frac{\ll}{z}$ & $\begin{array}{l}\text { مी } \\
\text { مٌ }\end{array}$ & $\begin{array}{l}10 \\
\stackrel{n}{n}\end{array}$ & $\stackrel{n}{\text { an }}$ & $?$ \\
\hline 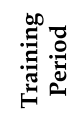 & $\stackrel{\Xi ّ}{0}$ & 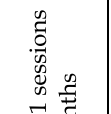 & 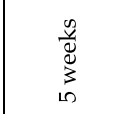 & $\begin{array}{l}\frac{n}{\tilde{g}} \\
\prod_{3}^{3} \\
n\end{array}$ & 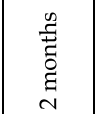 & 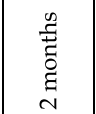 & $\begin{array}{l}\frac{y}{\ddot{g}} \\
3 \\
\sum_{n}^{0}\end{array}$ & $\begin{array}{l}\text { 足 } \\
\text { है } \\
\text { घ } \\
\text { N }\end{array}$ & 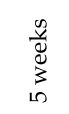 \\
\hline 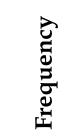 & 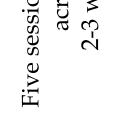 & 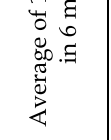 & $\stackrel{\vec{\pi}}{\overline{0}}$ & $\stackrel{\overrightarrow{\tilde{\Xi}}}{\vec{a}}$ & 辛 & 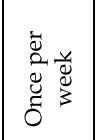 & 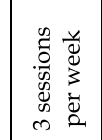 & 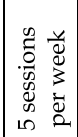 & 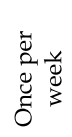 \\
\hline 咅芯芯 & 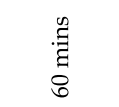 & 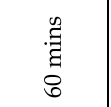 & 它泀 & 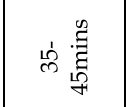 & 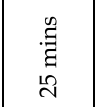 & 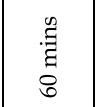 & 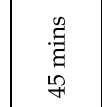 & 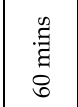 & 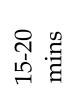 \\
\hline$\sum_{0}^{\grave{D}}$ & 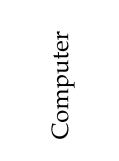 & 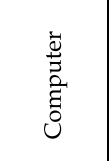 & 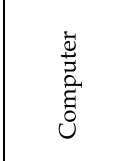 & $\begin{array}{l}\text { जे } \\
\vec{z} \\
\text { gे }\end{array}$ & 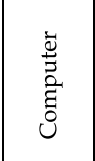 & 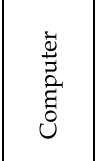 & 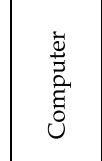 & 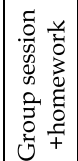 & 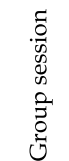 \\
\hline 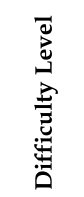 & 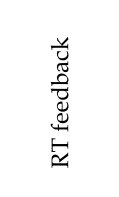 & 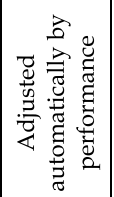 & 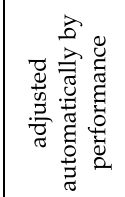 & 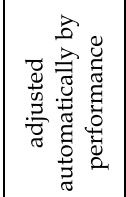 & 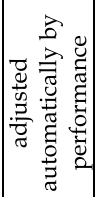 & 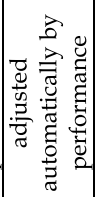 & 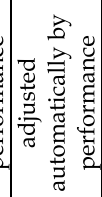 & 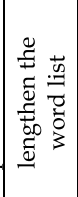 & 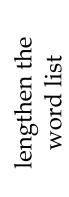 \\
\hline 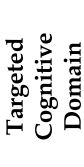 & 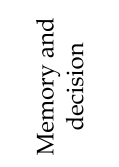 & 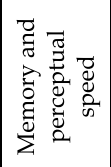 & $\begin{array}{l}\text { है } \\
\text { हूँ } \\
\text { है }\end{array}$ & 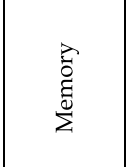 & 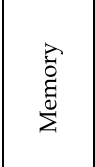 & 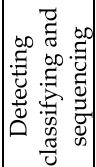 & 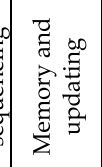 & 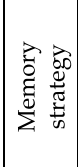 & 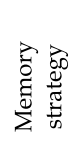 \\
\hline 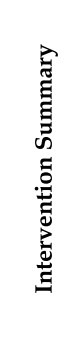 & 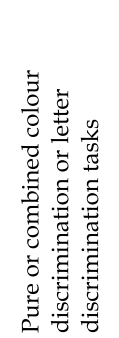 & 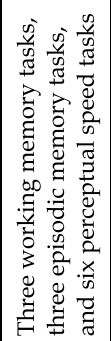 & 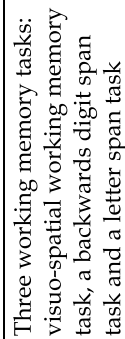 & 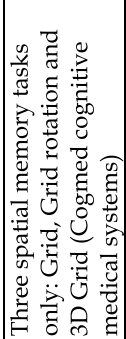 & 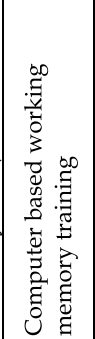 & 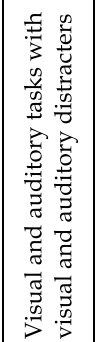 & 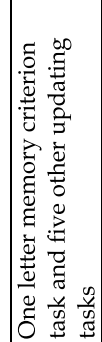 & 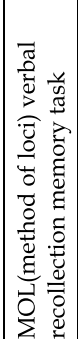 & 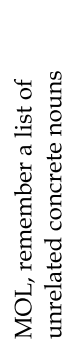 \\
\hline : & 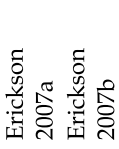 & 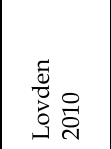 & 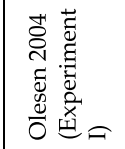 & 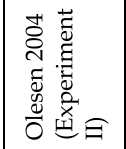 & 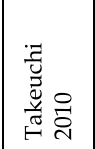 & 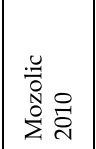 & 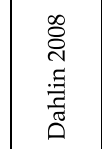 & 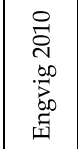 & 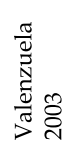 \\
\hline
\end{tabular}

Table 1. Summary of brain training interventions with MRI outcomes. 
consisted of different memory-based exercises (i.e., unidomain) (Dahlin et al., 2008; Erickson et al., 2007a, 2007b; Lovden et al., 2010; Olesen et al., 2004; Takeuchi et al., 2010). BT exercises were generally custom-designed by the research group, although one study investigated a multi-domain commercial program which included detecting, classifying, and/or sequencing with audio and visual distracters (Mozolic et al., 2010). Non-computerized BT studies used a specific mnemonic strategy known as the Method of Loci (MoL) (Engvig et al., 2010; Valenzuela et al., 2003). Further BT details are available in Table 1.

For most of the computerized BT interventions, difficulty level was automatically adjusted based on performance on previous tasks, whereas the Erickson group utilized continuous real-time feedback (response time) to help motivate and challenge subjects (Erickson et al., 2007a). Across all studies, training was session-based, varying form 20 minutes to 60 minutes per session. Frequencies of BT also varied from one session per week to daily. The duration of interventions were generally around two months ) (Dahlin et al., 2008; Engvig et al., 2010; Mozolic et al., 2010; Olesen et al., 2004; Takeuchi et al., 2010; Valenzuela et al., 2003), except for one 6 month training study (Lovden et al., 2010) and two 2-week training studies (Erickson et al., 2007a, 2007b).

Definition of control training in RCTs was predominantly a no-intervention wait-and-see condition in 6 studies, whilst one study used an active control training condition, which comprised an educational lecture program and quizzes (Mozolic et al., 2010).

\subsection{Types of MRI}

Five studies used an event-related fMRI approach, employing in-scanner tasks either identical or highly similar to the offline training exercises (Erickson et al., 2007a, 2007b; Olesen et al., 2004). One fMRI study is unique for investigating functional BT-related changes related to both the trained task as well as to non-trained tasks within the scanner (Dahlin et al., 2008). Two studies investigated BT-induced changes to white matter fractional anisotropy (FA) and mean diffusivity (MD) using DTI (Lovden et al., 2010; Takeuchi et al., 2010). Another study used perfusion MRI (pMRI) to investigate BT effects on whole-brain cerebral blood flow (Mozolic et al., 2010). Finally, one study employed MR spectroscopy (MRS) to explore biochemical change before and after BT in several cortical and subcortical areas (Valenzuela et al., 2003).

Whilst all studies were selected for employing a baseline and post-training scan, one study conducted dual baseline scans in one experiment, and 5 serial scans over 5 weeks during BT in another experiment (Olesen et al., 2004). T1 structural MRI (sMRI) were common to all studies, however only two studies have specifically reported structural BT outcomes (Engvig et al., 2010; Lovden et al., 2010). Three out of ten studies used a 3 Tesla scanner, remaining studies used 1.5 Tesla field strength. No study specifically reported the presence or absence of hardware scanner changes or upgrades during the follow-up period.

\subsection{Approaches to MRI pre-processing}

Three main software platforms were used to perform MRI preprocessing: Four papers used different versions (SPM99, SPM2, SPM5) of Statistical Parametric Mapping (SPM, http://www.fil.ion.ucl.ac.uk/spm/) (Dahlin et al., 2008; Mozolic et al., 2010; Olesen et al., 2004; Takeuchi et al., 2010), two studies used FSL (FMRIB Software Library http://www.fmrib.ox.ac.uk/fsl/ ) (Erickson et al., 2007a, 2007b), and one study was based on Freesurfer (http://surfer.nmr.mgh.harvard.edu/ ) (Engvig et al., 2010). Further MRI preprocessing information is summarized in Table 2. 


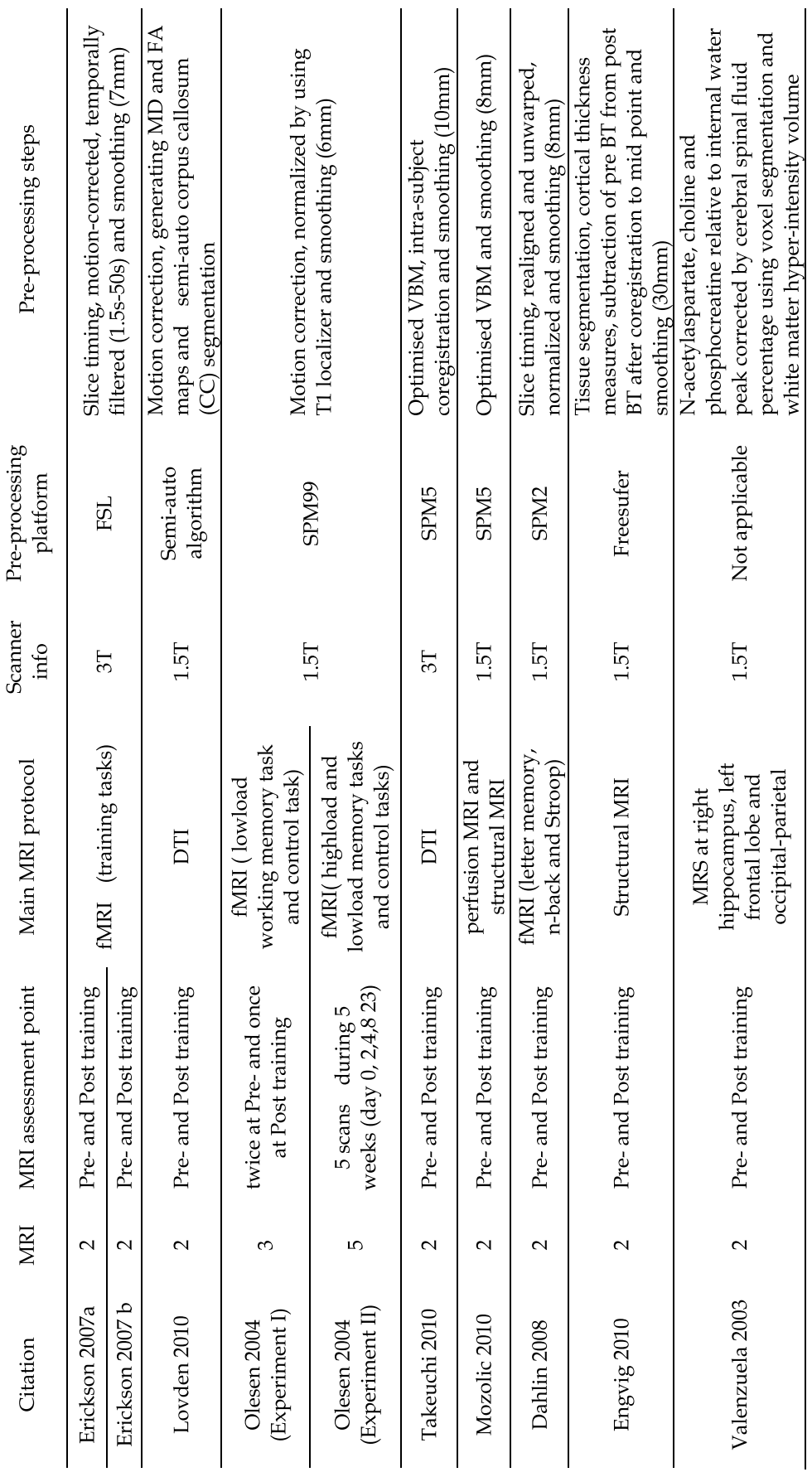

Table 2. Hardware and preprocessing information of reviewed studies. 
Irrespective of MRI modality or research interest, the goal of preprocessing should be to prepare data so that further analytical assumptions are valid (Klein et al., 2009). For example, motion correction and spatial normalization maximizes the likelihood that a particular voxel property comes from same location across subjects. In the ten studies reviewed, fMRI preprocessing procedures were similar, including slice timing, motion correction, normalization, and smoothing. pMRI, DTI and sMRI studies created samplespecific template for coregistration and normalization purpose. Two studies (Mozolic et al., 2010; Takeuchi et al., 2010) followed the Optimized VBM (Good et al., 2001) approach, and one study created subject-specific templates by averaging image pairs across pre- and postsessions (Engvig et al., 2010). Finally, the Lovden group used a semi-automatic algorithm for analysis of the corpus callosum (Niogi et al., 2007).

MRS studies require no geometric preprocessing. Rather, quantitative MRS assessment of neurometabolites may be influenced by scanning parameters such as shimming and receiver gain. MRS studies generally report relative metabolic signal intensity against a reference signal, and creatine is by far the most common reference signal. However, because subclinical degenerative disease and the intervention itself could hypothetically alter resting state phosphocreatine-creatine turnover (Valenzuela \& Sachdev, 2001), we have used tissue-water as a more reliable reference signal in studies of ageing and BT (Valenzuela et al., 2003).

\subsection{Approaches to MRI statistical inference}

The General Linear Model (GLM) assumes an individual's MRI signal of interest is a function of a 'ground truth' signal modified by one or more experimental conditions and affected by error. The strengths (Friston et al., 2007) and weaknesses (Haynes, 2011) of the GLM approach therefore apply generally to the present set of fMRI, sMRI and DTI studies. In the context of longitudinal BT studies, statistical inference was mainly geared at testing Group (BT vs control) $\times$ Time (Pre vs Post-BT) interactions. In addition, one study carried out a regression analysis when analyzing DTI, using total BT amount (completed sessions) as the covariate of interest (Takeuchi et al., 2010).

When testing the null hypothesis, BT MRI studies have generally adopted a 'mass univariate' voxel-by-voxel test, either across the whole-brain or restricted to some ROI defined by prior knowledge. This approach assumes each voxel (or larger cluster of voxels) is necessarily an independent observation, an assumption that contradicts brain biology and introduces a significant multiple-comparison problem (Nichols \& Hayasaka, 2003). Four studies used cluster-level correction (Dahlin et al., 2008; Erickson et al., 2007a, 2007b; Mozolic et al., 2010; Olesen et al., 2004), and one study voxel-level correction (Engvig et al., 2010). Some studies designed an initial experiment, and such first-level results were consequently used as an explicit mask for the next experiment (Dahlin et al., 2008; Erickson et al., 2007a, 2007b; Mozolic et al., 2010; Olesen et al., 2004). In this case, close attention is required to avoid non-independence errors (Kriegeskorte et al., 2009; Vul et al., 2009). Interestingly, one study used a split-half validation approach that uses a more relaxed multiple-correction threshold in one half of the sample to generate hypotheses for rigorous (but more constrained) testing in the other half of the sample (Engvig et al., 2010). Notably, alternative network approaches that consider covariance patterns across and between ensembles of brain locations (Haynes 2011), including Partial Least Squares analysis (Krishnan et al., 2011), Independent Components Analysis (Biswal \& Ulmer, 1999; Calhoun et al., 2001), or graph-based analysis (Bullmore \& Sporns, 2009), have not yet been applied to BT studies. Further details are available in Table 3. 


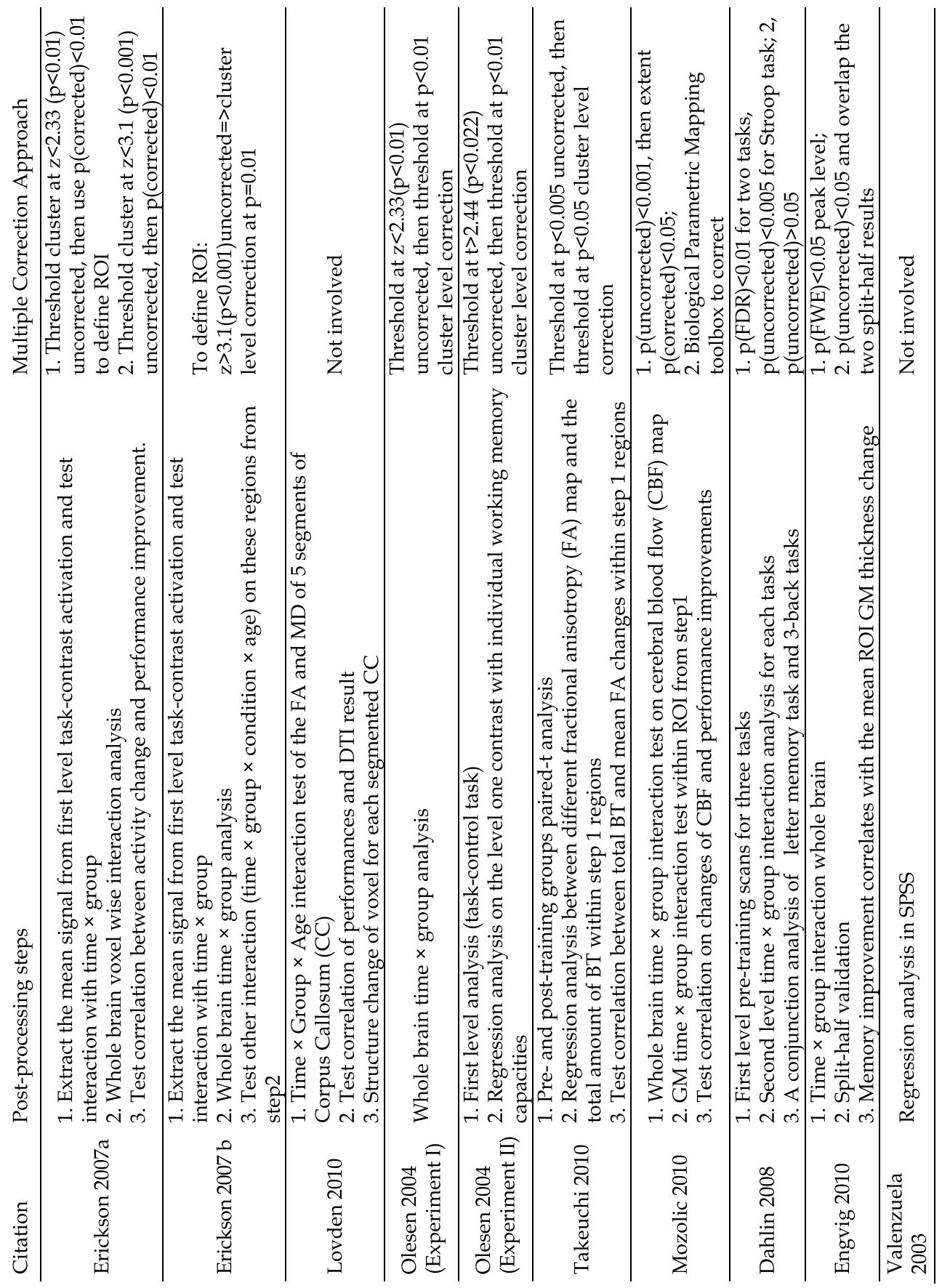

Table 3. Post-processing and statistical correction details. 


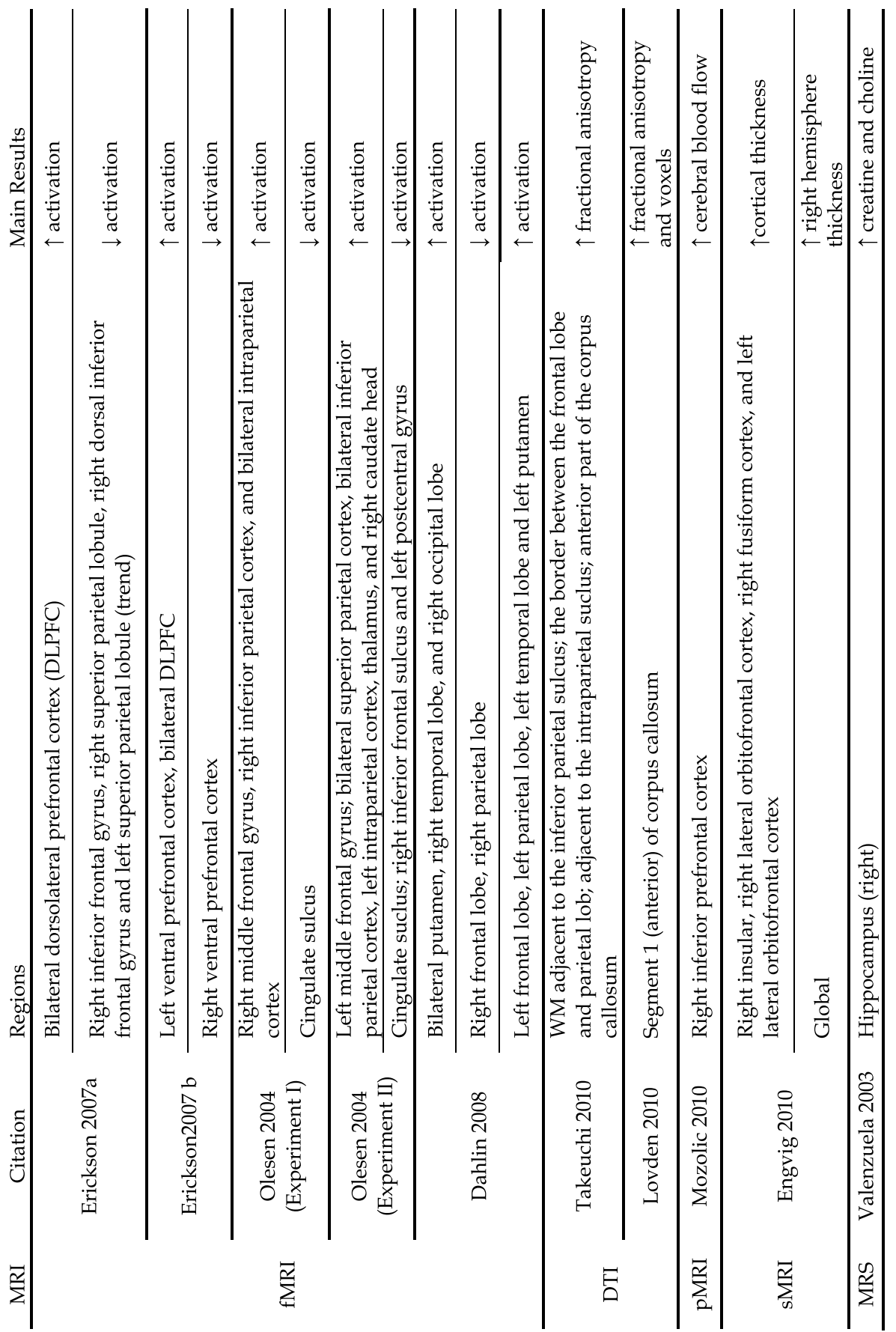

Table 4. Summary of MRI results of brain training in healthy adults. 


\subsection{Neuroimaging outcomes in BT trials}

All MRI studies have to date revealed significant training-induced brain changes. Moreover, there is some overlap between studies in terms of topographical distribution. Training-related adaptation in the frontal lobe is most common. In fact, frontal lobe functional changes were reported in all fMRI studies, although the direction of changes was not consistent, and the precise localization of differences also varied (see Table 4). Even in the same experiments, there was evidence of both increased and reduced activation in distinct frontal lobe areas (Erickson et al., 2007a, 2007b). These functional changes are also supported by BT-related increments to cerebral blood flow (Mozolic et al., 2010), and in one study, increased cortical thickness (Engvig et al., 2010). Since all BT (either explicitly or implicitly) requires repetitive high-load engagement of working memory, it is not altogether surprising that frontal lobe plasticity is consistently implicated. Differences in BT design may help explain regional heterogeneity in these fMRI studies.

Another working-memory related area is the parietal lobe (Osaka et al., 2007), also implicated in multimodal integration (Fogassi et al., 2005), and hence potentially relevant to BT. Greater superior or inferior parietal lobe activity was detected in five fMRi studies after training compared with the untrained groups (Dahlin et al., 2008; Erickson et al., 2007a, 2007b; Olesen et al., 2004), with the exception of one study which found reduced activation in the right superior parietal lobe (Dahlin et al., 2008). Furthermore, a DTI study found increased fractional anisotropy (FA) in white matter regions adjacent to the inferior parietal sulcus, as well as at the border between the frontal and parietal lobe (Takeuchi et al., 2010). Two studies have investigated the corpus callosum (CC) using DTI, and both revealed increased FA of the anterior CC after BT (Lovden et al., 2010; Takeuchi et al., 2010). Finally, only one study has focused on BT-related changes in the hippocampus, arguably the brain's most plastic area (Burke \& Barnes, 2006; Gage et al., 2008), using MRS after a five-week Method of Loci trial (Valenzuela et al., 2003). Increased phosphocreatine was found in the hippocampus, but not other grey and white matter areas, suggestive of an activitydependent upregulation of cellular-energy resting state, potentially of neuroprotective benefit (Brustovetky et al., 2001) in an area highly susceptible to degeneration.

There were also several differences in outcomes between studies, and so it is important to consider possible moderating factors. Session number or frequencies are unlikely to have had a major impact as they were relatively consistent between studies. Age, however, may be salient to BT outcomes. For example, in Erickson and colleagues' study (Erickson et al., 2007b), whilst a significant group $\times$ time interaction was for both elderly and young subjects at the dorsal prefrontal cortex bilaterally, the direction of the effects were opposite: in the older subjects there was reduced activation after BT, and increased activation amongst young subjects. Age differences have also been observed in a DTI study, whereby FA increased after BT only in the older group (Lovden et al., 2010).

\section{Discussion}

\subsection{A biological insight into the trained brain}

One of the major unresolved challenges for the BT field is to adequately demonstrate transfer or generalizability of outcomes (Gates \& Valenzuela, 2010; Valenzuela \& Sachdev, 2009). Individuals will predictably improve on almost any trained task - in clinical terms this is rather trivial unless gains can also be demonstrated in non-trained tasks. Neuroimaging studies are only beginning to address this issue. For example, one study 
found that the effect of training in one task translates to functional brain changes in nontrained tasks (Dahlin et al., 2008). Brain imaging studies can therefore provide independent biological evidence about the impact of BT on brain structure, function and biochemistry.

So far, BT studies have been universally positive, each study reporting at least one significant brain imaging outcome. It is of course impossible to assess the role of publication bias, as null studies may have been self-censored by authors, or rejected by editors and reviewers. The field is also manifestly young, only 10 studies were found following a systematic search, across a mix of BT designs, approaches, MRI modalities and subjects. Nevertheless, a number of studies point to the key role of frontal lobe plasticity in potentially mediating BT benefits. All fMRI studies have so far found changes in this region, and as mentioned, this may reflect the heavy working memory demands of BT itself. Interestingly, repetitive practice of working memory problems does not necessarily lead to straightforward increases (in terms of signal change or spread of suprathreshold voxels) in task-related functional activity. Rather, a complex series of increases and decreases in brain activity have been observed. BT may therefore lead to two major types of functional adaptations including (Lustig et al., 2009): i) task-related hyperactivation, where the network of brain regions that normally subserves a given task becomes primed to activate, and ii) efficiency gains, where for a less extensive brain response, the same (or increased) cognitive proficiency is possible.

The cellular and molecular mechanisms that underlie BT-related frontal lobe plasticity are currently not known. Environmental enrichment, (in part) a model for BT in animals, is known to produce a wide range of neurobiological changes, including enhanced synaptic plasticity, neurogenesis and angiogenesis, as well as macroscopic structural changes including increased brain volume (Nithianantharajah \& Hannan, 2006; Valenzuela et al., 2007). Interestingly, one sMRI has found that extensive memory training ( 2 months, 5 days a week) can translate into increased cortical thickness in the frontal lobe (Engvig et al., 2010), and two DTI studies further suggest frontal lobe structural plasticity in the form of increased FA in the anterior corpus callosum (Lovden et al., 2010; Takeuchi et al., 2010). The temporal dynamics of such structural BT changes are not understood, but studies of mental activity outside of our BT definition do provide some clues. Knowledge acquisition amongst college students led to persistent hippocampal volumetric increases even 3 month after the end of study (Draganski et al., 2006), whilst motor training studies suggest gray matter volume reaches a zenith after just 7 days of training and gains are reversed three months later (Boyke et al,. 2008; Driemeyer et al., 2008). With sufficient practice, functional BT effects may transform into detectable structural brain changes. From a practical viewpoint, sMRI plasticity may take longer to develop, or simply produce subtle changes, and hence studies with this outcome in mind need to pay attention to adequate BT dosage, power and sample size.

\subsection{Limitations and challenges for the field}

Whilst BT research has so far employed the full range of MR modalities, the field conspicuously lacks multi-modal studies. Each modality has its strengths and weaknesses, and so combining MR approaches will allow the clearest insight into putative neurobiological mechanisms. Use of network-based analyses will also help integrate findings across modalities, as well as recognize the interconnected and dynamic nature of human brain plasticity (Bullmore \& Sporns, 2009). However, of more fundamental concern is the absence of any active control group in almost all reviewed RCTs. Since BT typically involves participants coming into a centre for some level of person-to-person instruction, as 
well as often undertaking training in group sessions, receiving personalized feedback, and a host of other non-specific stimulatory factors, it is altogether unclear whether results so far reflect the benefits of BT specifically, or the neural manifestation of social contact, motivation, generic mental activity, and other Hawthorne effects. Future studies must employ active control conditions to ensure that valid neurobiological inferences are possible. Similarly, whilst BT often implicates working memory-related brain regions such as the prefrontal lobe, few studies have demonstrated a clear correlation between MRI-changes and BT-induced cognitive benefits (Engvig et al., 2010; Erickson et al., 2007a, 2007b). Of course, when testing for such links there are numerous technical MR processing pitfalls that could lead to spurious results. This has been graphically illustrated by Thomas et al., 2009, who found that a period of mirror-reading training led, alternatively, to either nil, modest, or widespread structural brain changes depending on which Voxel-Base-Morphometry assumptions were made, or even which software package was chosen. Recently, a systematic comparison of different sMRI software platforms found each had strengths and weaknesses, depending on the nature of the question (de Bresser et al., 2011). Clearly, for the field to advance on solid ground, claims of BT-related plasticity should not be pipelinedependent (Valenzuela, et al., in press), and the strongest results will be those with some level of cross-validation, either though the use of multiple imaging modalities, verification by manual methods, or parameter-based sensitivity testing.

Finally, a technical factor that is often overlooked is the role of hardware MRI upgrades during the intervention period (Ridgway et al., 2008). These routinely occur, often outside the control of the investigator, and become increasingly relevant in longitudinal studies. Reporting of any hardware changes during a BT trial should be standard, and if this change selectively affects some subjects but not others, at a bare minimum this information should be added to analyses as a nuisance covariate.

\section{Conclusions}

Neuroimaging studies of BT emphasize the brain's potential to adapt and change during the whole of life. Functional BT changes are most frequently implicated, with consistent findings of altered activity patterns in frontal and parietal lobe areas. Cross-validation of these results is also emerging with MR studies reporting BT-induced structural, blood flow and biochemical adaptation. Multimodal imaging investigation of BT is needed, recognizing that structural BT-related plasticity may be subtle and have a different time course to functional BT-related plasticity. A major challenge for the field is to start to draw connections between BT-related changes in brain structure and function to the cognitive benefits increasingly evident in clinical studies. Future studies should also take care to design active control conditions, as well as ensure that results are not overly influenced by arbitrary processing decisions.

\section{References}

Biswal, B. B., \& Ulmer, J. L. (1999). Blind source separation of multiple signal sources of fMRI data sets using independent component analysis. J Comput Assist Tomogr, Vol.23, No.2, (1999/03/30), pp. 265-271, ISSN 0363-8715 
Boyke, J., Driemeyer, J., Gaser, C., Buchel, C., \& May, A. (2008). Training-induced brain structure changes in the elderly. J Neurosci, Vol.28, No.28, (2008/07/11), pp. 70317035, ISSN 1529-2401

Brustovetsky, N., Brustovetsky, T., \& Dubinsky, J. M. (2001). On the mechanisms of neuroprotection by creatine and phosphocreatine. J Neurochem, Vol.76, No.2, (2001/02/24), pp. 425-434, ISSN 0022-3042

Bullmore, E., \& Sporns, O. (2009). Complex brain networks: graph theoretical analysis of structural and functional systems. Nat Rev Neurosci, Vol.10, No.3, (2009/02/05), pp. 186-198, ISSN 1471-0048

Burke, S. N., \& Barnes, C. A. (2006). Neural plasticity in the ageing brain. Nat Rev Neurosci, Vol.7, No.1, (2005/12/24), pp. 30-40, ISSN 1471-003X

Calhoun, V. D., Adali, T., McGinty, V. B., Pekar, J. J., Watson, T. D., \& Pearlson, G. D. (2001). fMRI activation in a visual-perception task: network of areas detected using the general linear model and independent components analysis. Neuroimage, Vol.14, No.5, 1080-1088, ISSN 1053-8119

Clare, L., \& Woods, R. T. (2004). Cognitive training and cognitive rehabilitation for people with early-stage Alzheimer's disease: A review. Neuropsychological Rehabilitation: An International Journal, Vol.14, No.4, 385 - 401, ISSN 0960-2011

Dahlin, E., Neely, A. S., Larsson, A., Backman, L., \& Nyberg, L. (2008). Transfer of learning after updating training mediated by the striatum. Science, Vol.320, No.5882, (2008/06/17), pp. 1510-1512, ISSN 1095-9203

de Bresser, J., Portegies, M. P., Leemans, A., Biessels, G. J., Kappelle, L. J., \& Viergever, M. A. (2011). A comparison of MR based segmentation methods for measuring brain atrophy progression. Neuroimage, Vol.54, No.2, (2010/10/05), pp. 760-768, ISSN 1095-9572

Draganski, B., Gaser, C., Kempermann, G., Kuhn, H. G., Winkler, J., Buchel, C., et al. (2006). Temporal and spatial dynamics of brain structure changes during extensive learning. J Neurosci, Vol.26, No.23, (2006/06/10), pp. 6314-6317, ISSN 1529-2401

Driemeyer, J., Boyke, J., Gaser, C., Buchel, C., \& May, A. (2008). Changes in gray matter induced by learning--revisited. PLoS One, Vol.3, No.7, (2008/07/24), pp. e2669, ISSN 1932-6203

Engvig, A., Fjell, A. M., Westlye, L. T., Moberget, T., Sundseth, O., Larsen, V. A., et al. (2010). Effects of memory training on cortical thickness in the elderly. Neuroimage, Vol.52, No.4, (2010/06/29), pp. 1667-1676, ISSN 1095-9572

Erickson, K. I., Colcombe, S. J., Wadhwa, R., Bherer, L., Peterson, M. S., Scalf, P. E., et al. (2007a). Training-induced functional activation changes in dual-task processing: an FMRI study. Cereb Cortex, Vol.17, No.1, (2006/02/10), pp. 192-204, ISSN 1047-3211

Erickson, K. I., Colcombe, S. J., Wadhwa, R., Bherer, L., Peterson, M. S., Scalf, P. E., et al. (2007b). Training-induced plasticity in older adults: effects of training on hemispheric asymmetry. Neurobiol Aging, Vol.28, No.2, (2006/02/17), pp. 272-283, ISSN 1558-1497

Fogassi, L., Ferrari, P. F., Gesierich, B., Rozzi, S., Chersi, F., \& Rizzolatti, G. (2005). Parietal lobe: from action organization to intention understanding. Science, Vol.308, No.5722, (2005/04/30), pp. 662-667, ISSN 1095-9203 
Friston, K., Ashburner, J., Penny, W., Keibel, S., \& Nicholas, M. (2007). Statistical parametric mapping : the analysis of functional brain images. London : Academic, ISBN 0123725607, London

Gage, F. H., Kempermann, G., \& Song, H. (Eds.). (2008). Adult neurogenesis. Cold Spring Harbor, N.Y. : Cold Spring Harbor Laboratory Press, ISBN 9780879697846, N.Y.

Gates, N., \& Valenzuela, M. (2010). Cognitive exercise and its role in cognitive function in older adults. Curr Psychiatry Rep, Vol.12, No.1, (2010/04/29), pp. 20-27, ISSN 1535-1645

Haynes, J. D. (2011). Multivariate decoding and brain reading: Introduction to the special issue. Neuroimage, Vol.56, No.2, (2011/03/31), pp. 385-386, ISSN 1095-9572

Klein, A., Andersson, J., Ardekani, B. A., Ashburner, J., Avants, B., Chiang, M. C., et al. (2009). Evaluation of 14 nonlinear deformation algorithms applied to human brain MRI registration. Neuroimage, Vol.46, No.3, (2009/02/07), pp. 786-802, ISSN 1095-9572

Kriegeskorte, N., Simmons, W. K., Bellgowan, P. S., \& Baker, C. I. (2009). Circular analysis in systems neuroscience: the dangers of double dipping. Nat Neurosci, Vol.12, No.5, (2009/04/28), pp. 535-540, ISSN 1546-1726

Krishnan, A., Williams, L. J., McIntosh, A. R., \& Abdi, H. (2011). Partial Least Squares (PLS) methods for neuroimaging: A tutorial and review. Neuroimage, Vol.56, No.2, (2010/07/27), pp. 455-475, ISSN 1095-9572

Lovden, M., Bodammer, N. C., Kuhn, S., Kaufmann, J., Schutze, H., Tempelmann, C., et al. (2010). Experience-dependent plasticity of white-matter microstructure extends into old age. Neuropsychologia, Vol.48, No.13, (2010/09/08), pp. 3878-3883, ISSN 1873-3514

Lustig, C., Shah, P., Seidler, R., \& Reuter-Lorenz, P. A. (2009). Aging, training, and the brain: a review and future directions. Neuropsychol Rev, Vol.19, No.4, (2009/10/31), pp. 504-522, ISSN 1573-6660

McGurk, S. R., Mueser, K. T., \& Pascaris, A. (2005). Cognitive training and supported employment for persons with severe mental illness: one-year results from a randomized controlled trial. Schizophr Bull, Vol.31, No.4, (2005/08/05), pp. 898-909, ISSN 0586-7614

McGurk, S. R., Twamley, E. W., Sitzer, D. I., McHugo, G. J., \& Mueser, K. T. (2007). A metaanalysis of cognitive remediation in schizophrenia. Am J Psychiatry, Vol.164, No.12, (2007/12/07), pp. 1791-1802, ISSN 0002-953X

Mozolic, J. L., Hayasaka, S., \& Laurienti, P. J. (2010). A cognitive training intervention increases resting cerebral blood flow in healthy older adults. Front Hum Neurosci, Vol.4, (2010/03/20), pp. 16, ISSN 1662-5161

Nichols, T., \& Hayasaka, S. (2003). Controlling the familywise error rate in functional neuroimaging: a comparative review. Stat Methods Med Res, Vol.12, No.5, (2003/11/06), pp. 419-446, ISSN 0962-2802

Niogi, S. N., Mukherjee, P., \& McCandliss, B. D. (2007). Diffusion tensor imaging segmentation of white matter structures using a Reproducible Objective Quantification Scheme (ROQS). Neuroimage, Vol.35, No.1, (2007/01/09), pp. 166174, ISSN 1053-8119

Nithianantharajah, J., \& Hannan, A. J. (2006). Enriched environments, experience-dependent plasticity and disorders of the nervous system. Nat Rev Neurosci, Vol.7, No.9, (2006/08/23), pp. 697-709, ISSN 1471-003X 
Osaka, N., Logie, R. H., \& D'Esposito, M. (2007). The cognitive neuroscience of working memory. Oxford ; New York : Oxford University Press, ISBN 978-0-19-857039-4, Oxford; New York

Takeuchi, H., Sekiguchi, A., Taki, Y., Yokoyama, S., Yomogida, Y., Komuro, N., et al. (2010). Training of working memory impacts structural connectivity. J Neurosci, Vol.30, No.9, (2010/03/06), pp. 3297-3303, ISSN 1529-2401

Thomas, A. G., Marrett, S., Saad, Z. S., Ruff, D. A., Martin, A., \& Bandettini, P. A. (2009). Functional but not structural changes associated with learning: an exploration of longitudinal voxel-based morphometry (VBM). Neuroimage, Vol.48, No.1, (2009/06/13), pp. 117-125, ISSN 1095-9572

Valenzuela, M., Bartres-Faz, D., Beg, F., Fornito, A., Merlo-Pich, E., Muller, U., et al. (in press). Neuroimaging as Endpoints in Clinical Trials: Are We There Yet? Perspective from the first Provence Workshop. Molecular Psychiatry.

Valenzuela, M., \& Sachdev, P. (2009). Can cognitive exercise prevent the onset of dementia? Systematic review of randomized clinical trials with longitudinal follow-up. Am J Geriatr Psychiatry, Vol.17, No.3, (2009/02/20), pp. 179-187, ISSN 1545-7214

Valenzuela, M. J., Jones, M., Wen, W., Rae, C., Graham, S., Shnier, R., et al. (2003). Memory training alters hippocampal neurochemistry in healthy elderly. Neuroreport, Vol.14, No.10, (2003/07/24), pp. 1333-1337, ISSN 0959-4965

Valenzuela, M. J., \& Sachdev, P. (2001). Magnetic resonance spectroscopy in AD. Neurology, Vol.56, No.5, (2001/03/23), pp. 592-598, ISSN 0028-3878

Valenzuela, M. J., Sachdev, P. S., Wen, W., Shnier, R., Brodaty, H., \& Gillies, D. (2000). Dual voxel proton magnetic resonance spectroscopy in the healthy elderly: subcorticalfrontal axonal $\mathrm{N}$-acetylaspartate levels are correlated with fluid cognitive abilities independent of structural brain changes. Neuroimage, Vol.12, No.6, (2000/12/09), pp. 747-756, ISSN 1053-8119

Vul, E., Harris, C., Winkielman, P., \& Pashler, H. (2009). Voodoo correlations in social neuroscience. Perspectives on Psychological Science, Vol.4, No.3, 274-290, ISSN 1745-6916 


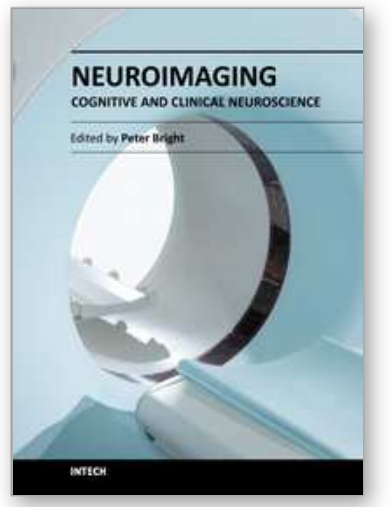

\author{
Neuroimaging - Cognitive and Clinical Neuroscience \\ Edited by Prof. Peter Bright
}

ISBN 978-953-51-0606-7

Hard cover, 462 pages

Publisher InTech

Published online 16, May, 2012

Published in print edition May, 2012

The rate of technological progress is encouraging increasingly sophisticated lines of enquiry in cognitive neuroscience and shows no sign of slowing down in the foreseeable future. Nevertheless, it is unlikely that even the strongest advocates of the cognitive neuroscience approach would maintain that advances in cognitive theory have kept in step with methods-based developments. There are several candidate reasons for the failure of neuroimaging studies to convincingly resolve many of the most important theoretical debates in the literature. For example, a significant proportion of published functional magnetic resonance imaging (fMRI) studies are not well grounded in cognitive theory, and this represents a step away from the traditional approach in experimental psychology of methodically and systematically building on (or chipping away at) existing theoretical models using tried and tested methods. Unless the experimental study design is set up within a clearly defined theoretical framework, any inferences that are drawn are unlikely to be accepted as anything other than speculative. A second, more fundamental issue is whether neuroimaging data alone can address how cognitive functions operate (far more interesting to the cognitive scientist than establishing the neuroanatomical coordinates of a given function - the where question).

\title{
How to reference
}

In order to correctly reference this scholarly work, feel free to copy and paste the following:

Chao Suo and Michael J. Valenzuela (2012). Neuroimaging Outcomes of Brain Training Trials, Neuroimaging Cognitive and Clinical Neuroscience, Prof. Peter Bright (Ed.), ISBN: 978-953-51-0606-7, InTech, Available from: http://www.intechopen.com/books/neuroimaging-cognitive-and-clinical-neuroscience/neuroimagingoutcomes-of-brain-training-trials

\section{INTECH}

open science | open minds

\section{InTech Europe}

University Campus STeP Ri

Slavka Krautzeka 83/A

51000 Rijeka, Croatia

Phone: +385 (51) 770447

Fax: +385 (51) 686166

www.intechopen.com

\section{InTech China}

Unit 405, Office Block, Hotel Equatorial Shanghai

No.65, Yan An Road (West), Shanghai, 200040, China

中国上海市延安西路65号上海国际贵都大饭店办公楼405单元

Phone: +86-21-62489820

Fax: $+86-21-62489821$ 
(C) 2012 The Author(s). Licensee IntechOpen. This is an open access article distributed under the terms of the Creative Commons Attribution 3.0 License, which permits unrestricted use, distribution, and reproduction in any medium, provided the original work is properly cited. 